\title{
Overweight and Obesity
}

\author{
Tina Cloney* \\ Millikin University, Illinois, USA \\ *Corresponding Author: Tina Cloney, Millikin University, Illinois, USA.
}

Received: January 20, 2020

Published: February 07, 2020

(C) All rights are reserved by Tina Cloney.

DOI: $10.31080 /$ ASNH.2020.04.0640

Rates of overweight and obesity are too high in both children and adults across the United States and most other countries across the world $[1,2]$. The prevalence of obesity in childhood has doubled in 73 countries and continues to grow in many other countries [3]. The rate of overweight and obesity across the world in 0 to 5 years olds increased from 32 million children to 41 million children in 2016, and 107.7 million children overall [3,4]. There has been more than a 30\% higher increase in the number of overweight or obese children in developing countries compared to developed countries. Overweight affects $21.4 \%$ of children in the United States [3]. Obesity affects $18.5 \%$ of children in the United States [6]. The age distribution among children is $13.9 \%$ of two to five year olds, $18.4 \%$ of six to 11 year olds, and $20.6 \%$ of 12 to 19 year olds [6]. Untreated childhood obesity often continues into adulthood [6].

Obesity affects $12 \%$ of adults (603.7 million) globally [3], and $39.8 \%$ in the Unites States [1]. While differences can be seen when comparing races, ethnicity, and education level, rates among all groups for both overweight and obesity are high (Hispanic 47\%, Non-Hispanic Black 46.8\%, Non-Hispanic White 38.0\%) [4]. Rates were lower in Non-Hispanic Asian adults (14.8\%) [1,4]. Rates of adult obesity continue to grow as well [3].

"Women, Infants and Children is a federal program that promotes healthy eating and provides nutrition education for infants and children up to age 5" [7]. Overweight and Obesity rates declined among some of these recipients by more than $3 \%$ from 2010 to 2016 in three states and three territories: New Jersey, New Mexico, Virginia, Guam, Northern Mariana Islands, and Puerto Rico. Note rates did increase $(.5 \%, .5 \%, 2.2 \%)$ in three other states: Alabama, North Carolina, and West Virginia [7].

Lifestyle diseases account for $70 \%$ of deaths globally. Some of these diseases include cardiovascular disease (i.e. heart attack and stroke), type 2 diabetes, high blood pressure, certain types of cancer, and tobacco-related respiratory disease [5]. Exercise, avoiding tobacco, and a healthy diet can significantly reduce risk of developing any one of these diseases. Overweight and obesity significantly increase the risk of chronic disease [5,8]. Type 2 diabetes rates among children and adolescents are as follows: $49.4 \%$ for Native Americans, 22.7 for Asian/Pacific Islanders, 19.4\% for African Americans, $17 \%$ for Hispanics, and 5.6\% for non-Hispanic Whites. Adolescents are often diagnosed in their teen years. The diagno- sis of Type 2 in the youth is occurring worldwide [9]. Rates of hypercholesterolemia were high among children: $7.4 \%$ overall $(6 \%$ 6-8 year olds; 7.3\% 9-11 year olds; 6.8\% 12-15 year olds; 8-9\% $16-19$ year olds) [10]. Obesity is a major contributor to high blood pressure in children [11]. One study found that $20.6 \%(\mathrm{~N}=1,066)$ of school children had high blood pressure (95th percentile) after adjusting for confounding variables with higher rates found among overweight children ( $>$ 85th percentile), the female population, children with acanthus nigricans, and the Hispanic population [12].

I worked as a pediatric dietitian for 16 years, concurrently as a lipid clinic dietitian, obesity clinic pediatric dietitian, while also providing child-adolescent nutrition seminars to the parents of children in the community with a pediatrician. I also counseled clients of all ages on an outpatient and inpatient basis. During this time I also covered the prenatal clinic. It quickly became apparent that new mothers did not know how to feed their newborns, toddlers, and children as they grew. Physicians are busy. Children were referred for weight loss counseling long after they were obese. There must be a more timely, proactive versus reactive approach to avoid effects on emotional health, mental health, and increased risk of lifestyle diseases (type 2 diabetes, high blood pressure, hyperlipidemia, bone and joint problems, etcetera). Since many children carry overweight and obesity into adulthood, it is logical for these efforts to occur earlier in childhood.

While young parents do not often seek guidance, they welcome guidance. A chef and I have participated in a grant program with Head Start multiple years, teaching teen parents how to shop on a budget, shop healthy (meals and snacks), read labels, cook healthy, etc. The program is a six-week program. The young mothers learn the first hour and apply the concepts they have learned the second hour (cooking different meals or going to the grocery store). The young mothers then take home the same ingredients to cook the meal for their family at home. The young mothers (and sometimes young fathers) truly enjoy the learning experience. They are able to try new foods, learn valuable nutrition information, learn how to cook, and learn new cooking techniques. Some mothers lose significant weight from the beginning of the program to the end of the program while learning valuable life skills. The chef and myself volunteer our time.

There are multiple professionals in the community willing to volunteer their time and experience (medical doctors or residents, 
registered dietitians, registered nurses, teachers, etcetera and students in college studying in these disciplines). Primary prevention efforts need to involve creative endeavors (1) registered dietitian screenings at provider offices, (2) mandatory nutrition education classes directed at different age levels at physician practices and public health departments, (3) safe places for our children to play, (4) sidewalks in all neighborhoods, (5) sidewalks for children to walk to and from school, (6) neighborhood watch programs to protect our children while playing outside, (7) education on the importance of balance in a child's life and a healthy lifestyle. Community leaders and members can brainstorm to find additional solutions to preventing overweight and obesity throughout all communities. The addition of these preventative efforts can supplement current efforts to reduce overweight, obesity, elevated screenings and the management of complications associated with chronic disease.

Multiple approaches have been created and delivered from a public health standpoint and medical care standpoint. Primary, secondary and tertiary prevention are vital to reducing rates of lifestyle diseases or complications from lifestyle diseases. Lifestyle intervention is very effective in promoting emotional health, mental health, and physical health. Primary prevention is vital before children adopt behaviors conducive to developing conditions once unknown in younger populations. It can also be very effective in treating conditions found during screenings such as elevated body weight, elevated blood pressure, increased waist circumference, increased body mass index, sedentary behavior, and hypercholesterolemia. Secondary prevention measures/screenings are essential in finding risk factors (high blood pressure, hypercholesterolemia, elevated body weight, elevated blood glucose) early in an effort to treat and reduce the risk of these factors progressing into hypertension, arteriosclerosis, atherosclerosis, type 2 diabetes or another chronic disease. Early education is vital. The same lifestyle practices to prevent chronic disease are the very ones to manage the chronic disease but do not include medications, surgeries, potential disability-adjusted life years or reductions in longevity. Efforts need to be directed toward elementary age children in an effort to prevent overweight and obesity versus combating overweight and obesity only after they present and throughout their lives.

\section{Bibliography}

1. Hales CM., et al. "Prevalence of Obesity Among Adults and Youth: United States". NCHS Data Brief, No. 288. 2015-2016 (2017).

2. Stevens GA., et al. "National, regional, and global trends in adult overweight and obesity prevalences". Population Health Metrics 10 (2012): 22.

3. GBD 2015 Obesity Collaborators. Effects of Overweight and Obesity in 195 Countries over 25 Years". The New England Journal of Medicine (2017): 13-27.

4. World Health Organization (WHO). Commission on Ending Childhood Obesity (2019).
5. Tabish SA. "Lifestyle Diseases: Consequences, Characteristics, Causes and Control". Cardiology and Current Research 9.30 (2017): 00326.

6. Centers for Disease Control and Prevention. Child Obesity Facts (2019).

7. Centers for Disease Control and Prevention. Obesity Among WIC - Enrolled Young Children (2019).

8. Xu S and Xue Y. "Pediatric Obesity: Causes, Symptoms, Prevention and Treatment". Experimental and Therapeutic Medicine 19 (2016): 15-20.

9. E'Adamo E and Caprio S. "Type 2 Diabetes in Youth: Epidemiology and Pathophysiology”. Diabetes Care 34 (2011): S161-S165.

10. Nguyen D., et al. "Abnormal Cholesterol Among Children and Adolescents in the United States, 2011 - 2014". NCHS Data Brief (2015).

11. Urrutia-Rojas X., et al. "High blood pressure in school children: prevalence and risk factors". BMC Pediatrics 6 (2006): 32.

12. Sharma AK., et al. "Prevalence and Severity of High Blood Pressure Among Children Based on the 2017 American Academy of Pediatric Guidelines". JAMA Pediatrics 172 (2018): 557-565.

\section{Assets from publication with us}

- Prompt Acknowledgement after receiving the article

- Thorough Double blinded peer review

- Rapid Publication

- Issue of Publication Certificate

- High visibility of your Published work

Website: https://www.actascientific.com/

Submit Article: https://www.actascientific.com/submission.php Email us: editor@actascientific.com

Contact us: +919182824667 